\title{
e-Interview
}

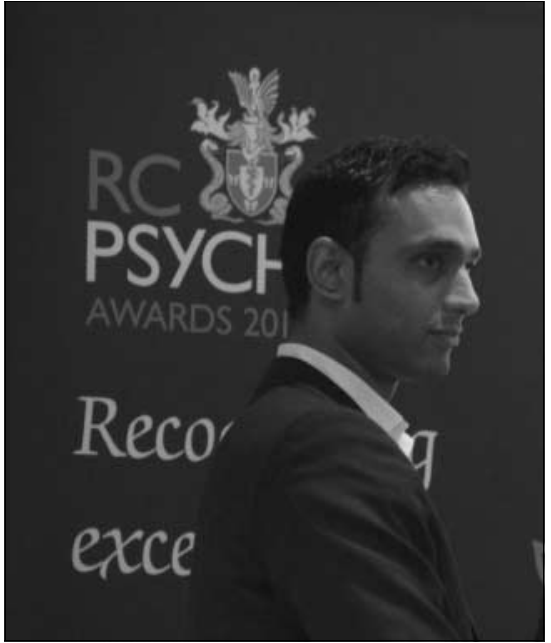

\section{Dr Kamran Ahmed}

Kamran Ahmed is a specialist registrar in psychiatry working in London. He is currently doing a Darzi Fellowship and recently won the Royal College of Psychiatrists national award for higher psychiatric trainee of the year. In 2011 he founded Medfest (www.medfest.co.uk), the UK's first and only national medical film festival with events aimed at medical students at nine universities around the UK. In 2012 the Festival expanded to 16 university sites had over 1000 attendees throughout the country.

\section{What gave you the idea for Medfest?} Medicine and cinema have a fascinating relationship. There have been some great films with medical themes, such as My Left Foot and One Flew Over the Cuckoo's Nest, but many of these have portrayed healthcare professionals and patients in controversial ways. It occurred to me that there is no medical film festival in this country to explore this and, like many other doctors, I love films, so I thought it would be a good idea to start one.

\section{Where does your interest in film come from? \\ What I find most appealing about films is their ability to literally turn ideas, no matter how fantastic, into reality. I used to invent and act out imaginary films as a child and the interest stuck with me until I eventually tried making a few films of my own. Films are also a powerful medium for communicating a message and affecting}

change, with the potential to reach a much larger audience than the printed word.

\section{Why do you think medicine is so} prominent in film?

Medicine provides the perfect material for films and television owing to the depth and range of emotions experienced by those in medical settings, from the patients to relatives and staff. The world of medicine is full of high-stakes drama since we are dealing with life and death situations every day and this can lead to wins, when things go well, and tragedy, when they do not. Throw in plenty of comic potential, ethical dilemmas and conflicted characters working under pressure and you have the perfect recipe for visual storytelling.

\section{What were the challenges in starting} Medfest?

Medfest was a large-scale national project so it took a lot of hard work by everyone involved. I was extremely fortunate to have a highly motivated team working on the festival, consisting of psychiatric trainees who worked with local university psychiatric societies to run the events. Between us, we came up with a programme, acquired funding, secured panellists for each event (including authors, film-makers, actors and eminent doctors), created a website, developed and printed posters and conducted an evaluation of the festival. Managing that amount of work alongside a full-time clinical post was a massive challenge in itself!

\section{The festival team consists mainly of} psychiatrists. Why is that?

I thought psychiatrists would be in the best position to organise this festival because many psychiatrists (and potential psychiatrists) have a creative streak. There are some striking similarities between film and psychiatry; both involve observation and communication and both are concerned with exploring personal relationships and incredible stories, often gripping and tragic.

\section{How did the festival go?}

Last year, more than 450 people attended Medfest events around the country and we received a great review in the Lancet. The evaluation consisted of audience members completing questionnaires before and after each event; $93 \%$ of respondents thought the event they attended was a success and $85 \%$ thought they left with a better understanding of how doctors are portrayed in film and how this affects the public perception of our profession (which was the theme of the festival); $45 \%$ of students were more likely to consider a career in psychiatry as a result of the event which was another one of our aims. This year's events went extremely well and we should have the evaluation results soon.

Tell us about this year's Medfest. This year the theme for Medfest was 'Healthscreen: understanding illness through film'. The programme explored the many facets of the depiction of illness in film. How effective are the messages communicated using public education films? What responsibility do films made for entertainment have to portray illnesses accurately and sensitively? These questions were debated by the panels of experts from the worlds of medicine and film at Medfest events around the country.

\section{What advice would you give to other} entrepreneurial doctors and medical students?

I would advise anyone wanting to start a project of this nature to make sure it is related to something they are very enthusiastic about; it makes the whole process far more enjoyable. It is very useful to gain senior support for the idea and even better if you are a member of a motivated committee or organisation and can get the other members on board. When managing the project, I would recommend thinking big, seeking lots of advice, making the most of individuals' strengths and delegating appropriately.

What are your hopes for the future of Medfest? And your own plans?

In the current financial climate attaining funding will be a challenge for future runs of the festival, but I hope we can keep attracting sponsorship and grants. I would also like to see Medfest become a festival that accepts submissions from healthcare professionals and students; after all, those who work in the field of medicine are best placed to tell the stories that they experience. As for myself, I am currently working on a writing project and hope to make more films alongside my work as a psychiatrist in the future.

For more information on Medfest visit www.medfest.co.uk.

Golnar Aref-Adib, Christopher Kowalski, Rory Conn

doi: 10.1192/pb.bp.112.038588 